\title{
LA INTERFERENCIA Y LA ESCUCHA (PENSAR HOY LA ESCUCHA CON LUIGI NONO)
}

\author{
Susana Jiménez Carmona \\ Universitat de Girona
}

\section{Resumen}

En este artículo se parte de la distinción entre escuchar y entender para plantear, siguiendo al compositor Luigi Nono, que se escucha lo que no se comprende, lo que no responde a lo ya sabido y escapa del código y de la repetición. La obra de Nono forma parte del pensamiento musical que, a lo largo del s. XX, ha cuestionado la contraposición entre ruido y sonido conduciendo a la ruptura tanto de las convenciones ligadas al concierto de música clásica como a los modos de oír lo que suena. En este marco, el compositor veneciano apuesta por la escucha como dispositivo cargado de enorme potencia política que manifiesta la capacidad disruptiva y de disenso del arte y de la música. Esta forma de plantear la escucha la hemos puesto en diálogo con pensadores actuales como Rancière y Tiqqun.

Palabras clave: ESCUCHA; INTERFERENCIA; COMPRENDER; SONIDO; POLÍTICA

\section{INTERFERENCE AND LISTENING (UNDERSTANDING LISTENING TODAY WITH LUIGI NONO)}

\section{Abstract}

In accordance with the composer Luigi Nono, this paper assumes the distinction between listening and understanding to raise that we listen to what is not understood, what does not respond to what was already known and escapes from the code and the repetition. The work of Nono is part of the musical thought that, throughout the 20th century, has questioned the distinction between noise and sound leading to the rupture of the conventions of classical music concert and the transformation of modes of hearing what sounds. In this context, the Venetian composer bet by the listening as a device loaded with enormous political power that shows the capacity of art and music to dissent and to disrupt. We have put this form of listening in dialogue with current as Rancière and Tiqqun thinkers.

Keywords: LISTENING; INTERFERENCE; TO UNDERSTAND; SOUND; POLITICAL

\section{AUSART}


Interferir: cruzar, interponer algo en el camino de otra cosa, o en una acción; causar interferencia; dicho de una señal: introducirse en la recepción de otra y perturbarla ${ }^{1}$.

Brouiller: mêler en agitant, en dérangeant; rendre trouble, altérer; rendre confus, troubler; désunir en provoquant une brouille ${ }^{2}$.

1 .

La información se distingue del ruido porque se le puede asignar cierto código, una relativa uniformización; en todos los casos en que el ruido no puede ser disminuido directamente por debajo de un cierto nivel, se opera una reducción del margen de indeterminación y de imprevisibilidad de las señales de información ${ }^{3}$.

(Tiqqun 2015, 172)

En una reciente visita a Madrid, le preguntaron a Helmut Lachenmann cómo llevaba lo de ser incomprendido por el público, a diferencia de lo que ocurre con los artistas contemporáneos que se dedican a otras artes ${ }^{4}$. La respuesta de Lachenmann fue rotunda: afirmó que quien a los pocos minutos de empezar a escuchar una de sus obras, se levanta molesto y se marcha, le entiende perfectamente. Es más, le entiende mejor que aquel que oye su música con complacencia, al igual que quien pasea su mirada por un museo o exposición. Estas palabras de Lachenmann recuerdan su texto de 1985, L'écoute est désarmée-sans l'écoute, recogido por Szendy en L'écoute. Allí Lachenmann rechaza esa pretendida escucha que se acerca a las cacofonías desesperadas de la música contemporánea como si se tratase de una excursión turística a nuevos mundos sonoros, a sonidos desconocidos. Tampoco entiende la escucha como una atención sensible a la significación para comprender aquello que se pueda estar diciendo. Para Lachenmann, la escucha implica un cambio en quien percibe, un extrañamiento de sí mismo, de las formas y los caminos preestablecidos, para abrir así la posibilidad de que la percepción y el entendimiento se transformen. Y ese exponerse, además de ser molesto, puede llegar a ser doloroso (Lachenmann 2000, 118-9). En su respuesta, el compositor añadió la pregunta de cuánto tiempo se soportaría estar sentado inmóvil y plenamente atento ante cualquier obra contemporánea de las que se exponen en los museos. 
Este rechazo a maneras de oír complacidas y comprensivas, satisfechas y distanciadas la comparte Lachenmann con quien fuera su maestro, Luigi Nono, ese caminante inagotable que no dejó de pensar acerca de la cuestión de la escucha durante los años 80 . Ascolta! fue para el veneciano una exhortación no sólo para quienes se acercan a su música, sino también para sí mismo y para quienes trabajaron con él (los intérpretes, los técnicos e ingenieros de sonido, u otros colaboradores). No en vano aparece la palabra 'ascolto' en el título de la obra en la que culminan muchas de las preocupaciones que acompañaron al compositor durante la última etapa de su vida: Prometeo, tragedia dell'ascolto. Para el último Nono, la escucha se convierte en un problema y una tarea que no atañen únicamente a lo estrictamente musical. Cómo vivimos, cómo nos relacionamos y cómo hacemos mundo están implicados en el cómo percibimos.

En diversas ocasiones manifestó Nono lo difícil que resulta escuchar. De entre ellas, destaca una breve comunicación que realizó en Ginebra el año 1983, L'errore come necessità, en la que señala que no sólo no escuchamos la música, sino tampoco el silencio o a los demás (Nono 2001, 522-3). En lugar de atender lo que se da, recurrimos de manera reiterada a lo que ya sabemos, para poder catalogar lo que oímos dentro de lo ya conocido y reencontrarnos cómodamente con nosotros mismos. Sólo damos cabida a las pequeñas diferencias que no impliquen poner en riesgo hábitos, prejuicios y certezas. No nos encontramos ante el caso de quien se niega a escuchar porque no comprende, sino ante quien deja de escuchar precisamente por comprender. Para Nono escuchar no es comprender ni entender. No se trata de tender hacia lo que se da para penetrarlo, rodearlo o contenerlo. No se trata de alcanzarlo para deducirlo o juzgarlo. Sino exponerse a lo que suena, disponerse hacia lo que se da para ser alcanzado, penetrado, afectado, alterado, con el riesgo que ello supone. Escuchar y entender o comprender disienten ${ }^{5}$.

2.

Se llama ruido a un comportamiento que escapa al control permaneciendo a la vez indiferente al sistema, lo que, por consiguiente, no puede ser tratado en una máquina binaria, reducido a un 0 o a un 1. Estos ruidos son las líneas de fuga, el deambular de 
los deseos que aún no han entrado en el circuito de valorización, lo no-inscrito ${ }^{6}$.

(Tiqqun 2015, 148)

Nono se muestra muy crítico con el modo en que se escucha la música en las salas de concierto, en las que prima la visualidad (la escucha frontal de las salas a la italiana) y en las que se busca una homogeneidad replicable que hace olvidar la singularidad de cada lugar y de cada obra musical en su desplegarse en el espacio, en el entretejerse de sonido y espacio. Esa dificultad en el escuchar no sólo compete a la actitud del público, del oyente. También es consecuencia de que lo que se ofrece ya está consumado, es repetitivo (Nono 2001, 302). De ahí la necesidad de que compositores, intérpretes, técnicos de sonido, arquitectos se pregunten a sí mismos cómo escuchan. A mediados de los años 70, Nono se sumió en un profundo cuestionamiento de su hacer y su pensar en tanto que compositor atravesado profundamente por la política. Durante esos años de silencio se fue encontrando con sus hábitos, prejuicios y gestos aprendidos y se propuso desaprender, no para hallar una escucha o un pensamiento más originarios o naturales, sino para posibilitar que surgieran otros modos de percibir, de relacionarse y de hacer con lo sonoro, con el espacio y el tiempo musicales, con los demás, con lo diferente y con lo otro. En definitiva, para abrir otros posibles. Cómo escuchamos, cómo hacemos, cómo pensamos está marcado profundamente por la cultura y por el momento en el que vivimos. Otros modos de percibir señalan otros modos de hacer y de pensar. No siempre hubo salas a la italiana, no siempre lo sonoro se entendió dentro del sistema tonal o del temperado. Nono no cree en la tabula rasa, pero sí apuesta por que el desaprender y el transformar esos modos es posible, pues ya acaecieron cambios en el pasado. Por ello, gustaba de trazar genealogías de otras maneras de escucha de lo sonoro (como el microtonalismo) o del espacio musical (el uso heterogéneo del espacio durante el Renacimiento o el Barroco), para rescatar inaudibles e inauditos que pueblan lo que ya suena.

También recurre Nono, como otros compositores que le son coetáneos, a la atención prestada a los sonidos del cotidiano y de la ciudad como ejemplo de otras escuchas al margen de esa escucha idealizada, y sin embargo tan sorda, que se produce y propicia dentro de las salas de conciertos (Nono 2001, 349). El compositor defendía que en nuestra vida cotidiana, en los ambientes acústicos en los que habitamos se da una enorme riqueza sonora que generalmente pasa desapercibida y que, si se le presta atención, nos permite descubrir otros sonidos que ya se están dando, sonidos que creemos imperceptibles, además de abrir y ampliar nuestra capacidad de percepción y de imaginación sonora 
(394). No se trata sólo de aumentar el inventario de sonidos, sino de cuestionar qué se considera apto para ser escuchado y qué se considera mero ruido o qué pasa desapercibido por considerarse inaudible. También persigue preguntarse qué espacios se consideran los apropiados o idóneos para la escucha. Así, por ejemplo, Nono habla de Venecia en tanto que espacio acústico, en tanto que 'multiverso' sonoro que no deja de contradecir el sesgado sistema de transmisión y escucha del sonido al que estamos habituados. Y para el compositor, este aumento de la percepción traería consigo un aumento de la posibilidad de acceder a diferentes y más variados modos de pensamiento (337).

3.

En el marco de la hipótesis cibernética, el pánico se entiende como un cambio de estado del sistema autorregulado?

(Tiqqun 2015, 148)

La escucha atenta fuera de los espacios dedicados a la música es algo que Nono ya puso en práctica antes de los 80 , aunque a partir de esta fecha se convierta en un problema sobre el que no deja de preguntarse y de compartir en sus obras, textos o entrevistas. De 1964 data La fabbrica illuminata, obra para voz y cinta magnética en la que se oyen los sonidos y las voces de los trabajadores de la Italsider Genova-Cornigliano, recogiendo las condiciones de vida y de trabajo en la siderúrgica. Una vez concluida, el compositor llevó esta obra a diferentes localidades italianas para confrontarla con obreros y estudiantes. Durante estos encuentros Nono se sorprende gratamente de que la discusión no se centra en si se trata o no de música, de si es ruido lo que suena, como sucedía en los ámbitos culturales y burgueses. El carácter de fenómeno artístico de la obra no se discute, sino la función de la misma para la lucha de los obreros -y las opiniones que recoge Nono son diversas al respecto- (Nono 2001, 104). De manera más explícita en los años sesenta, Nono buscó cargar su obra de denuncia social y de promesa de emancipación para actuar en la vida misma. Las fronteras entre arte y no arte se hacen porosas en una música que pretende denunciar tanto las relaciones sociales como el lugar que en ellas le corresponde al arte interviniendo en las condiciones de producción de la propia música -el lenguaje, la técnica y la tecnología, o las 
relaciones entre intérpretes, compositor y público-. La huella de Walter Benjamin en Nono es profunda.

El pensamiento de Rancière en torno al arte y a la política puede ayudar a acercarse al hacer noniano. El filósofo afirma en relación al arte crítico de los años sesenta que la autocrítica del arte se combina con la crítica a los mecanismos de la dominación estatal y mercantil (Rancière 2012, 66). Rancière plantea que lo político en el arte no se refiere a los mensajes que se transmiten o al modo de representar los conflictos sociales -que en el caso de Nono también están presentes-, sino a cómo se cuestionan las propias funciones, y a cómo se traza una esfera de lo sensible y se distribuyen lugares e identidades -dónde y quiénes escuchan-, lo perceptible y lo imperceptible -qué se deja o no de escuchar-, además de a qué clase de tiempo y espacio se instituyen ${ }^{8}$ (34). Pero durante las últimas décadas del s. XX, cambia el modo en que se dan estos cuestionamientos y trazados en el arte más crítico: de un arte que buscaba resaltar las contradicciones de un mundo marcado por la explotación y buscaba cuestionar el lugar del arte y de sus instituciones en ese mundo conflictivo, se ha pasado un arte marcado por las categorías del consenso (148). Y en torno al consenso centra Nono su crítica durante los años 80.

4.

En primer lugar, provocar el pánico querrá decir extender la niebla-interferencias de fondo que se superpone a la activación de los bucles retroactivos y que dificulta el registro de las desviaciones de comportamiento por parte del aparataje cibernético (...). La niebla-interferencias es el vector privilegiado de la revuelta?

(Tiqqun 2015, 173)

Nono no dejó de apostar por la posibilidad de cambiarnos a nosotros mismos y de transformar el mundo. Sabedor de que hasta lo más íntimo está atravesado por lo social, durante sus últimos años insistió en explorar y abrir nuevas posibilidades mediante la escucha entendida como el exponerse a ser afectado y alterado por lo que suena, por los otros, por lo diferente, por lo inaudito, convencido de que cambiar el modo en el que percibimos transforma cómo pensamos y cómo hacemos mundo ${ }^{10}$. Para Nono, sin duda, merecía la pena este riesgo de dejarse sorprender y afectar, a pesar de las dificultades que 
conlleva. Siempre puede surgir lo inesperado y ocurrir una 'catástrofe'. Pero para ello no podemos limitarnos a una escucha comprensiva, una escucha tolerante que acepta indiferente las diferencias. En la época del pensamiento único, cuando reina el consenso en el que se pretende ajustar y acomodar todo, mientras guerras, conflictos y miserias se perpetúan, no basta con añadir nuevas opciones en el abanico de la elección. En su continuo situarse en los límites de la audibilidad, en su explorar sin tregua lo sonoro, el silencio y el espacio musical mediante el empleo de nuevas tecnologías, la escucha compartida con intérpretes y técnicos y la inmersión en los lugares en los que se ejecutaban sus obras, Nono busca infringir las reglas del juego para tratar de abrir posibles impensados e inauditos. El compositor quiere emplazarnos en el conflicto y la confrontación que hacen aflorar nuestros prejuicios y expectativas, quiere conducirnos a desencuentros que, en lugar de enriquecer el catálogo de opciones y selecciones que portamos con nosotros, lo desencajen y lo pongan en cuestión mostrando nuestra vulnerabilidad (Nono 2001, 531). Exponerse atentos a la confrontación y al desacuerdo nos arriesga a sufrir interferencias que no sólo rasgan el paraguas que llevamos desplegado haciéndonos ver algo de lo que permanecía cubierto y de lo que lo cubre, sino que permiten que lo posible nos cale ${ }^{11}$.

\section{Referencias}

Celedón, Gustavo. 2015. Philosophie et expérimentation sonore. París: L'Harmattan

Deleuze, Gilles \& Felix Guattari. 1993. ¿Qué es filosofía? Traducción de Thomas Kauf. BarceIona: Anagrama

Lachenmann, Helmut. 2000. “L'écoute est désarmée-sans l'écoute”. En L'écoute, editado por Peter Szendy, 115-45. París: L'Harmattan

Nancy, Jean-Luc. 2002. À l'écoute. París: Galilée

Nono, Luigi. 2001. Scritti e colloqui. Lucca: Ricordi

Rancière, Jacques. 2012. El malestar en la estética. Traducción, Gabriela Villalba. Madrid: Clave intelectual.

Tiqqun (colectivo). 2009. "L'hypothèse cybernétique". En Tout a failli, vive le communisme!, 22339. París: La Fabrique

- 2015. La hipótesis cibernética. Traducción, Raúl Suárez Tortosa y Santiago Rodríguez Rivarola. Madrid: A. Machado

Notas

${ }^{1}$ Definición extraída del Diccionario de la RAE.

${ }^{2}$ Extraído de Le Petit Robert Dictionnaire de la Langue Française (2004). 
3 "L'information se distingue du bruit parce qu'on peut assigner un certain code, une relative uniformisation à l'information; dans tous les cas où le bruit ne peut être abaissé directement au-dessous d'un certain niveau, on opère une réduction de la marge d'indétermination et d'imprévisibilité des signaux" (Tiqqun 2009, 331).

${ }^{4}$ Junio de 2015, durante el encuentro mantenido con el compositor en el Goethe-Institut de Madrid.

${ }^{5}$ En esta disonancia entre escuchar y entender/comprender resuena una tradición de pensamiento que se remonta a Nietzsche y que podemos encontrar más recientemente en el $\grave{A}$ l'écoute de Jean-Luc Nancy, quien llega a afirmar que sólo escuchamos lo que no entendemos, de ahí el lugar privilegiado que otorga a la música contemporánea que persiste e insiste en sacarnos de los caminos conocidos.

6 'On appelle 'bruit', un comportement qui échapperait au contrôle tout en restant indifférent au système, ce qui par conséquent ne peut pas être traité par une machine binaire, réduit à un 0 ou à un 1. Ces bruits, ce sont les lignes de fuite, les errances des désirs qui ne sont pas encore rentrés dans le circuit de la valorisation, le non-inscrit" (Tiqqun 2009, 308).

7 "Dans le cadre de l'hypothèse cybernétique, la panique est comprise comme un changement d'état du système autorégulé" (Tiqqun 2009, 308).

${ }^{8}$ El tratamiento del espacio y el tiempo es clave a la hora de entender el planteamiento político de Nono, pero no podemos entrar aquí en su análisis por la complejidad del mismo.

9 "Provoquer la panique voudra donc d'abord dire étendre le brouillard de fond qui se surimpose au déclenchement des boucles rétroactives et qui rend coûteux l'enregistrement des écarts de comportement par l'appareillage cybernétique (...). Le brouillard est le vecteur privilégié de la révolte" (Tiqqun 2009, 332).

${ }^{10}$ En este sentido, Rancière y Lachenmann se muestran de acuerdo con Nono: "L'émancipation, elle, commence quand on remet en question l'opposition entre regarder et agir, quand on comprend que les évidences qui structurent ainsi les rapports du dire, du voir et du faire appartiennent elles-mêmes à la structure de la domination et de la sujétion" (Celedón 2015, 117).

"Montrer l'interdépendance des difficultés et des possibilités de l'écoute, qui sont aussi celles de la pensée, du sentiment, de la connaissance, de la communication dans tous les domaines" (Lachenmann 2000, 144).

11 "En un texto violentamente poético, Lawrence describe lo que hace la poesía: los hombres incesantemente se fabrican un paraguas que les resguarda, en cuya parte inferior trazan un firmamento y escriben sus convenciones, sus opiniones; pero el poeta, el artista, practica un corte en el paraguas, rasga el propio firmamento, para dar entrada a un poco del caos libre y ventoso y para enmarcar en una luz repentina una visión que surge a través de la rasgadura" (Deleuze \& Guattari 1993, 204) 